\title{
Article \\ Evaluation of the Expression of miR-486-3p, miR-548-3p, miR-561-5p and miR-509-5p in Tumor Biopsies of Patients with Oral Squamous Cell Carcinoma
}

\author{
Ata Garajei ${ }^{1,2}$, Milad Parvin ${ }^{3}$, Hady Mohammadi ${ }^{4}$, Abdolamir Allameh ${ }^{5}$, Azin Hamidavi ${ }^{5}$, \\ Masoud Sadeghi ${ }^{6}$, Azadeh Emami ${ }^{7}$ and Serge Brand $8,9,10,11,12, *$ (D)
}

check for updates

Citation: Garajei, A.; Parvin, M.; Mohammadi, H.; Allameh, A.; Hamidavi, A.; Sadeghi, M.; Emami, A.; Brand, S. Evaluation of the Expression of miR-486-3p, miR-548-3p, miR-561-5p and miR-509-5p in Tumor Biopsies of Patients with Oral Squamous Cell Carcinoma. Pathogens 2022, 11, 211. https://doi.org/10.3390/ pathogens11020211

Academic Editors: Agostino Guida, Giuseppe Pannone and Marco Annunziata

Received: 14 December 2021 Accepted: 2 February 2022

Published: 5 February 2022

Publisher's Note: MDPI stays neutral with regard to jurisdictional claims in published maps and institutional affiliations.

Copyright: (C) 2022 by the authors. Licensee MDPI, Basel, Switzerland. This article is an open access article distributed under the terms and conditions of the Creative Commons Attribution (CC BY) license (https:// creativecommons.org/licenses/by/ $4.0 /)$.
1 Department of Oral and Maxillofacial Surgery, School of Dentistry, Tehran University of Medical Sciences, Tehran 1416753955, Iran; atagarajei@tums.ac.ir

2 Department of Head and Neck Surgical Oncology and Reconstructive Surgery, Cancer Institute, School of Medicine, Tehran University of Medical Sciences, Tehran 1416753955, Iran

3 Department of Oral and Maxillofacial Surgery, School of Dentistry, Bushehr University of Medical Sciences, Bushehr 7514633341, Iran; m.parvin@bpums.ac.ir

4 Department of Oral and Maxillofacial Surgery, Fellowship in Maxillofacial Trauma, Health Services, Kurdistan University of Medical Sciences, Sanandaj 6617713446, Iran; hadi.mohammadi@muk.ac.ir

5 Department of Clinical Biochemistry, Faculty of Medical Sciences, Tarbiat Modares University, Tehran 1416753955, Iran; allameha@modares.ac.ir (A.A.); azihamidaviasl@yahoo.com (A.H.)

6 Department of Biology, Science and Research Branch, Islamic Azad University, Tehran 1416753955, Iran; masoud.sadeghi@srbiau.ac.ir

7 Department of Anesthesiology, School of Medicine, Iran University of Medical Sciences, Tehran 1416753955, Iran; emami.a@iums.ac.ir

8 Sleep Disorders Research Center, Kermanshah University of Medical Sciences, Kermanshah 6719851115, Iran

9 Center for Affective, Stress and Sleep Disorders, University of Basel, Psychiatric Clinics, 4002 Basel, Switzerland

10 Substance Abuse Prevention Research Center, Kermanshah University of Medical Sciences, Kermanshah 6715847141, Iran

11 Department of Sport, Exercise and Health, Division of Sport Science and Psychosocial Health, University of Basel, 4052 Basel, Switzerland

12 School of Medicine, Tehran University of Medical Sciences, Tehran 1416753955, Iran

* Correspondence: serge.brand@upk.ch

\begin{abstract}
Background and objective: Oral squamous cell carcinoma (OSCC) is the most common head and neck malignancy. Expression patterns of microRNAs (miRNAs) can direct us in identifying valuable biomarkers for the prognosis of different neoplasms. Inappropriate regulation of miRNAs during physiological procedures can result in malignancies including OSCC. The aim of the present study was to evaluate the expression of miR-486-3p, miR-561-5p, miR-548-3p, and miR-509-5p in tissue biopsy samples with and without OSCC. Materials and methods: This case-control study was conducted on 17 healthy and 17 OSCC tissue biopsy samples. The expression of miRNAs was assessed using quantitative real-time PCR (q-RT-PCR) after RNA extraction from normal and cancer tissues and cDNA synthesis. Results: The means of miRNA-486-3p, miR-561-5p, and miR-548-3p expression were significantly different between OSCC and control groups $(p<0.001)$, but there was no significant difference in means of miR-509-5p expression between OSCC and control groups $(p=0.179)$. Conclusions: The findings of this study revealed that the expression of miR-486-3p and miR-561-5p was significantly lower in cancer samples compared to normal tissue samples. On the other hand, miR-548-3p expression increased in the OSCC group compared to the control group.
\end{abstract}

Keywords: oral squamous cell carcinoma (OSCC); microRNA (miRNA); real time PCR; gene expression

\section{Introduction}

Oral squamous cell carcinoma (OSCC) is the sixth most common cancer, with an annual incidence rate of more than 300,000 globally [1]. This type of cancer is the most 
malignant oral and maxillofacial tumor and comprises $90 \%$ of oral cancers [2,3]. The fiveyear survival rate of OSCC is $50 \%$, as the majority of the patients are diagnosed at late stages [4]. Regardless of the technological and biological advancements, the prognosis of OSCC has not changed over the past decade, and the incidence of OSCC has increased. Therefore, there is a need for more advancement in the development of diagnostic and prognosis prediction tools in clinical fields.

MicroRNA (miRNA) is a small non-coding single-stranded RNA that binds to its complementary sequence, which is mainly located on three prime untranslated regions (3'-UTR) in mRNA and inhibits translocation through the RNA-induced silencing complex (RISC) [5,6]. More than $30 \%$ of human genes are regulated by miRNAs; therefore, these miRNAs control cellular, physiological, and developmental procedures and have an important role in cell proliferation, differentiation, and apoptosis $[7,8]$. As these procedures are deregulated in cancer, not surprisingly, many studies have been conducted to assess the relationship between miRNAs and carcinogenesis [9]. MiRNAs are generally encoded by endogenous genes and have suppressive effects on post-transcriptional regulation of their target genes by suppressing mRNA translation or degradation. This mediates the subsequent activation or blocking of downstream signaling pathways associated with oral malignancies [10]. Expression of significant miRNA differences between normal tissue, potential malignancies, and oral cancer specimens suggests that miRNA may be used as an independent prognostic marker [11,12].

Molecular markers including DNA sequencing, gene expression, and epigenetic markers have been extensively studied in the development and progression of OSCC [13-16]. However, their specificity to this type of malignancy has not been approved. Based on the more recent reports it appears that changes in the expression of small non-coding RNA such as microRNA (miRNA) during OSCC could be a more reliable marker for the cancer prognosis and diagnosis. Clinical studies clearly show a good relationship between specific miRNA expression and clinical parameters such as tumor metastasis, relapse, and survival in OSCC patients. Lin et al. [17] showed in their meta-analysis the potential of miRNAs, as OSCC diagnostic markers were assessed. The meta-analysis included eight articles; findings were mixed and inconsistent. It appeared that differences in the study design, sample sizes, sampling types, and source or population explained the mixed and inconclusive pattern of results [17]. Furthermore, findings of three meta-analyses [18-20] in 2018 showed some controversies regarding the miRNA expression in OSCC; the authors concluded that differences in sample characteristics might have biased the blurred and inconsistent pattern of results of their meta-analyses. As regards the geographical distribution of the studies, Troinao et al. [18] showed in their meta-analysis that 14 out of 15 studies assessed miRNAs in OSCC were performed in China, Taiwan, or Japan (East and Southeast Asia), while just one study was performed in Denmark among Europeans [21]. In addition, numerous miRNAs have been shown to be expressed differently in many studies at the OSCC, and despite the growth of the miRNA literature and their specific expression status in a variety of tissues and diseases, each new study presents a new result that ethnic differences in the subjects could be one of the main causes of these differences [22]. Therefore, there was no report from other regions, such as Iran or even any Middle-Eastern countries.

Some miRNAs have been confirmed to act as tumor suppressors in cancers such as miRNA-486-3p [23], miR-548b-3p [24], miR-561-5p [25] and miR-509-5p [26]. Based on this information, this study was designed to assess the changes in expression of specific miRNA molecules, which could be implicated in the prognosis and treatment approaches of OSCC in Iran. More specifically, changes in expression of selected miRNA, more specifically in miR-486-3p, miR-561-5p, miR-548-3p, and miR-509-5p, have been examined and compared to normal biopsies of healthy individuals. 


\section{Materials and Methods}

\subsection{Study Procedure}

This case-control study was designed to assess the expression of miRNAs. To this end, seventeen tissue samples (13 males and 4 females) of patients with OSCC, and 17 tissue samples of healthy controls (13 males and 4 females) were gathered and analyzed between August 2017 and August 2018. Participants were selected from patients who were referred to the Shariati and Sina Hospitals and the Imam Khomeini Cancer Institute (Kermanshah, Iran). Patients who had either the documented OSCC diagnosis or who based on their physical examinations were suspicious for OSCC and thus underwent histopathological assessment were included as the case group. Participants in the control group were selected from patients who were referred to the dentistry department for impacted wisdom teeth extraction. Participants were fully informed about the study aims, the voluntary study participation, and the anonymous data handling. Thereafter, all participants signed the written informed consent form. Next, among participants with OSCC, biopsies were obtained from various oral, lingual, and gingival regions. Among participants in the control condition, tooth follicle samples were collected.

\subsection{Inclusion Criteria}

For individuals with OSCC, the key inclusion criterion was the documented histopathological diagnosis of OSCC in oral biopsies. For healthy individuals, the key inclusion criteria were an impacted wisdom tooth and the lack of history for malignancy and similar lesions. Next, for all participants, the signed written informed consent was mandatory, and the minimum age of participants was 18 years.

\subsection{Exclusion Criteria}

For all participants, any history of systemic, acute, or chronic inflammatory diseases was an exclusion criterion.

\subsection{Sociodemographic and General Health Information}

Participants reported on their age (years), gender (male or female at birth), smoking history (yes, no), metastasis (yes, no), neck dissection (yes, no), and the relapse (positive, negative).

\subsection{Total RNA and miRNA Extraction}

Fresh tissue samples were cut in $0.5 \mathrm{~cm}$ sections and immediately placed in tubes containing $0.5 \mathrm{~mL}$ RNAlater ${ }^{\circledR}$ buffer (Ambion, Austin, TX, USA). Then, samples were transferred to the laboratory by following the guidelines for transport and maintenance of specimens. The RNAlater was extracted using the miRNeasy mini kit (Qiagen, Hilden, Germany). Total RNA, including miRNA, extraction was performed based on manufacturer guidelines. The quality and quantity of the extracted RNA were assessed using a Nanodrop Spectrophotometer ${ }^{\mathrm{TM}}$ (2000c, Thermo Fisher Scientific, Wilmington, DE, USA) at $260 \mathrm{~mm}$ and $270 \mathrm{~mm}$ wavelengths. Overall, the concentration of extracted RNAs ranged between 200 and $1000 \mathrm{ng} / \mu \mathrm{L}$. The 260/280 ratio was approximately 2.13 . Then, samples were frozen at $-80{ }^{\circ} \mathrm{C}$ till assessment.

\section{6. cDNA Synthesis and $q-R T-P C R$}

The single-stranded cDNA was synthesized after RNA extraction. Then, the expression of miR-486-3p, miR-561-5p, miR-548-3p, and miR-509-5p were assessed based on the guidelines by the miRCURY LNA ${ }^{\mathrm{TM}}$ Universal RT miRNA PCR manufacturer (Exiqon, Vedbaek, Denmark). RNA samples were primarily diluted to $5 \mathrm{ng} / \mu \mathrm{L}$. The thermal protocol for cDNA synthesis in $20 \mu \mathrm{L}$ volumes was as follows; 60 min incubation at $42{ }^{\circ} \mathrm{C}, 5 \mathrm{~min}$ incubation at $95{ }^{\circ} \mathrm{C}$, and cooling to $4{ }^{\circ} \mathrm{C}$. Synthesized cDNA was transported to the freezer to be stored at $-20^{\circ} \mathrm{C}$. Then gene expression was evaluated based on the SYBR Green method using the ABI StepOnePlus ${ }^{\mathrm{TM}}$ Real-time PCR system 
(Applied Biosystems, Carlsbad, CA, USA) on $10 \mu \mathrm{L}$ of samples. The thermal protocol included primary denaturation at $95^{\circ} \mathrm{C}$ for $10 \mathrm{~min}$, amplification $\left(40\right.$ cycles at $95{ }^{\circ} \mathrm{C}$ for $10 \mathrm{~s})$, and incubation at $60^{\circ} \mathrm{C}$ for one minute. The housekeeping U6 small nuclear RNA (U6 snRNA) was used for normalizing the expression. The desired exact mature miRNA sequences were obtained from the miRBase website. Specific primers for target genes and housekeeping genes were designed using the Allele ID software based on SYBR Green q-RT-PCR technique. Replication products of q-RT-PCR were assessed using melting curve analysis in order to assess the specificity of replication. The real-time quantitative PCR primers used were miR-486-3p forward: 5'-GGCAGCTCAGTACAGGATAAA-3', miR-548-3p forward: $5^{\prime}$-ATTGGAACGATACAGAGAAGATT- $3^{\prime}$, miR-561-5p forward: $5^{\prime}$ CGCGATCAAGGATCTTAAACTTTGCC-3' ${ }^{\prime}$, and miR-509-5p forward: $5^{\prime}$-TTCTCCATGGT GGTGAAGACGCCA- $3^{\prime}$. Expression of miRNAs was identified based on the threshold cycle (CT). Relative expression was calculated using $2^{-\Delta \Delta C T}$ after normalization with the reference gene.

\subsection{Statistical Analysis}

The $2^{-\Delta \Delta C T}$ equation was used to assess the desired miRNA expression in tumor tissue in relation to normal tissue. The level of significance was set at alpha $<0.05$. All statistical computations were performed with SPSS ${ }^{\circledR} 22.0$ (IBM Corporation, Armonk, NY, USA) for Windows ${ }^{\circledR}$. We used Cohen's d (for the independent samples $t$-test) as an effect size used to indicate the standardized difference between two means. A $p$-value less than 0.01 was statistically significant.

\section{Results}

This study evaluated the expression of miR-486-3p, miR-561-5p, miR-548-3p, and miR-509-5p in tissue samples from 17 patients with OSCC and 17 healthy individuals.

Table 1 provides the descriptive demographic and clinical characteristics, separately for participants in the OSCC and in the control condition. Participants' age was 66.17 $(\mathrm{SD}=10.47)$ years for those in the OSCC condition, and $69.10(\mathrm{SD}=60.46)$ years for those in the control condition. Gender distribution was thirteen males and four females in each group. In the OSCC group, eight (47\%) were smokers; in the control condition, six (35\%) were smokers. In the OSCC condition, ten (59\%) had metastasis, and seven out of seventeen had a history of neck dissection.

Table 1. Demographic and clinical characteristics of the study subjects.

\begin{tabular}{cccc}
\hline \multirow{2}{*}{ Variable } & & OSCC Group & Control Group \\
$\mathbf{n}=\mathbf{1 7}$ & $\mathbf{n}=17$ \\
\hline \multirow{2}{*}{ Age (years \pm SD) } & & $66.17 \pm 10.47$ & $69.10 \pm 60.46$ \\
Gender & Male & $13(76 \%)$ & $13(76 \%)$ \\
& Female & $4(24 \%)$ & $4(24 \%)$ \\
Relapse & Positive & $7(41 \%)$ & $0(0.0 \%)$ \\
& Negative & $10(59 \%)$ & $17(100.0 \%)$ \\
Smoking history & Yes & $8(47 \%)$ & $6(35 \%)$ \\
& No & $9(53 \%)$ & $11(65 \%)$ \\
Metastasis & Yes & $10(59 \%)$ & $0(0.0 \%)$ \\
Neck dissection & No & $7(41 \%)$ & $17(100.0 \%)$ \\
history & Yes & $7(41 \%)$ & $0(0.0 \%)$ \\
Abbreviations: OSCC, oral squamous cell carcinoma; SD, standard deviation. & $17(100.0 \%)$ \\
\hline
\end{tabular}

3.1. Evaluation of the Expression ( $\triangle C T$ ) of miR-486-3p, miR-561-5p, miR-548-3p, miR-509-5p in the OSCC and Control Condition

Table 2 provides the descriptive and statistical indices of miR-486-3p, miR-561-5p, miR-548-3p, and miR-509-5p between the OSCC and control condition. Compared to the control condition, the OSCC condition showed lower miR-486-3p and miR-561-5p levels, 
and higher miR-548-3p levels. No differences were observed for miR-509-5p. Figure 1 provides the graphical summary.

Table 2. Distribution (mean \pm SD) of the expression of miRNAs among OSCC and control.

\begin{tabular}{cccc}
\hline Variable & $\begin{array}{c}\text { OSCC Group } \\
\mathbf{n}=\mathbf{1 7}\end{array}$ & $\begin{array}{c}\text { Control Group } \\
\mathbf{n}=\mathbf{1 7}\end{array}$ & $\boldsymbol{t}$-Test; Cohen's d \\
\hline miR-486-3p & $-2.21 \pm 2.20$ & $5.78 \pm 2.47$ & $\mathrm{t}(32)=9.95^{* * *}, \mathrm{~d}=-3.65(\mathrm{~L})$ \\
miR-561-5p & $-0.28 \pm 1.42$ & $6.97 \pm 4.07$ & $\mathrm{t}(32)=6.93^{* * *}, \mathrm{~d}=-2.37(\mathrm{~L})$ \\
miR-548-3p & $5.51 \pm 2.83$ & $2.05 \pm 1.62$ & $\mathrm{t}(32)=-4.36^{* * *}, \mathrm{~d}=1.50(\mathrm{~L})$ \\
miR-509-5p & $2.20 \pm 5.49$ & $0.33 \pm 0.25$ & $\mathrm{t}(32)=-1.40, \mathrm{~d}=0.48(\mathrm{~S})$ \\
\hline
\end{tabular}

Abbreviations: SD, standard deviation; OSCC, oral squamous cell carcinoma. Notes: ${ }^{* * *} p<0.001 . \mathrm{S}=$ small effect size; $\mathrm{L}=$ large effect size.

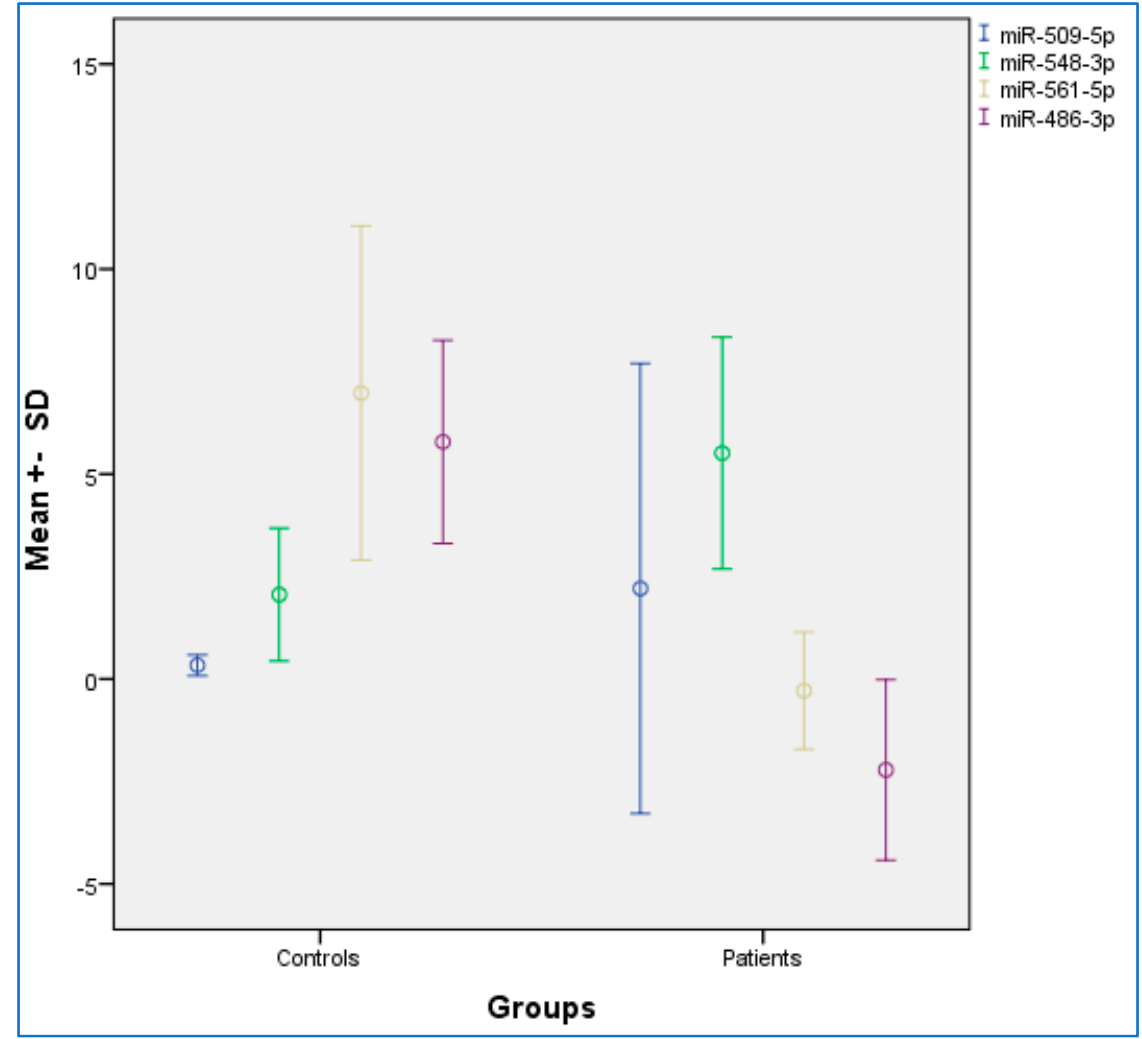

Figure 1. Distribution chart for the mean expression data among oral squamous cell carcinoma (OSCC) and control groups. SD, standard deviation. Error bar: 95\% confidence interval.

3.2. Correlational Associations between the Expression of $m i R-486-3 p, m i R-561-5 p, m i R-548-3 p$, and miR-509-5p Together

Table 3 provides the correlational associations between miR-486-3p, miR-561-5p, miR548-3p, and miR-509-5p. Higher miR-486-3p values were statistically significantly associated with higher miR-561-5p values and lower miR-548-3p values. Higher miR-561-5p values were statistically significantly associated with lower miR-548-3p values. MiR-509-5p values were statistically unrelated to miR-486-3p, miR-561-5p, and miR-548-3p values. 
Table 3. Correlational associations between the expression of miR-486-3p, miR-561-5p, miR-548-3p, and miR-509-5p together.

\begin{tabular}{llcccc}
\hline & & miR-486-3p & miR-561(5) & miR-548-3p & miR-509-5p \\
\hline miR-486-3p & Pearson Correlation & - & $0.726 * *$ & $-0.521 * *$ & -0.187 \\
miR-561-5p & Pearson Correlation & & - & $-0.553 * *$ & -0.131 \\
miR-548-3p & Pearson Correlation & & - & 0.093 \\
miR-509-5p & Pearson Correlation & & & - \\
\hline Notes: ${ }^{* *}=p<0.01$. & & &
\end{tabular}

\subsection{Sensitivity and Specificity}

The receiver operating characteristic (ROC) curve was used to assess the sensitivity and specificity of miRNAs (Figure 2). The ROC curves of miR-486-3p, miR-561-5p, miR548-3p, and miR-509-5p revealed the probability of them as valuable biomarkers with area under curves (AUCs) of 1.000, 0.983, 0.114, and 0.294, respectively. The ROC curve revealed that, based on AUC, miR-486-3p had the highest sensitivity and specificity, and the least sensitivity and specificity were observed for miR-548-5p.

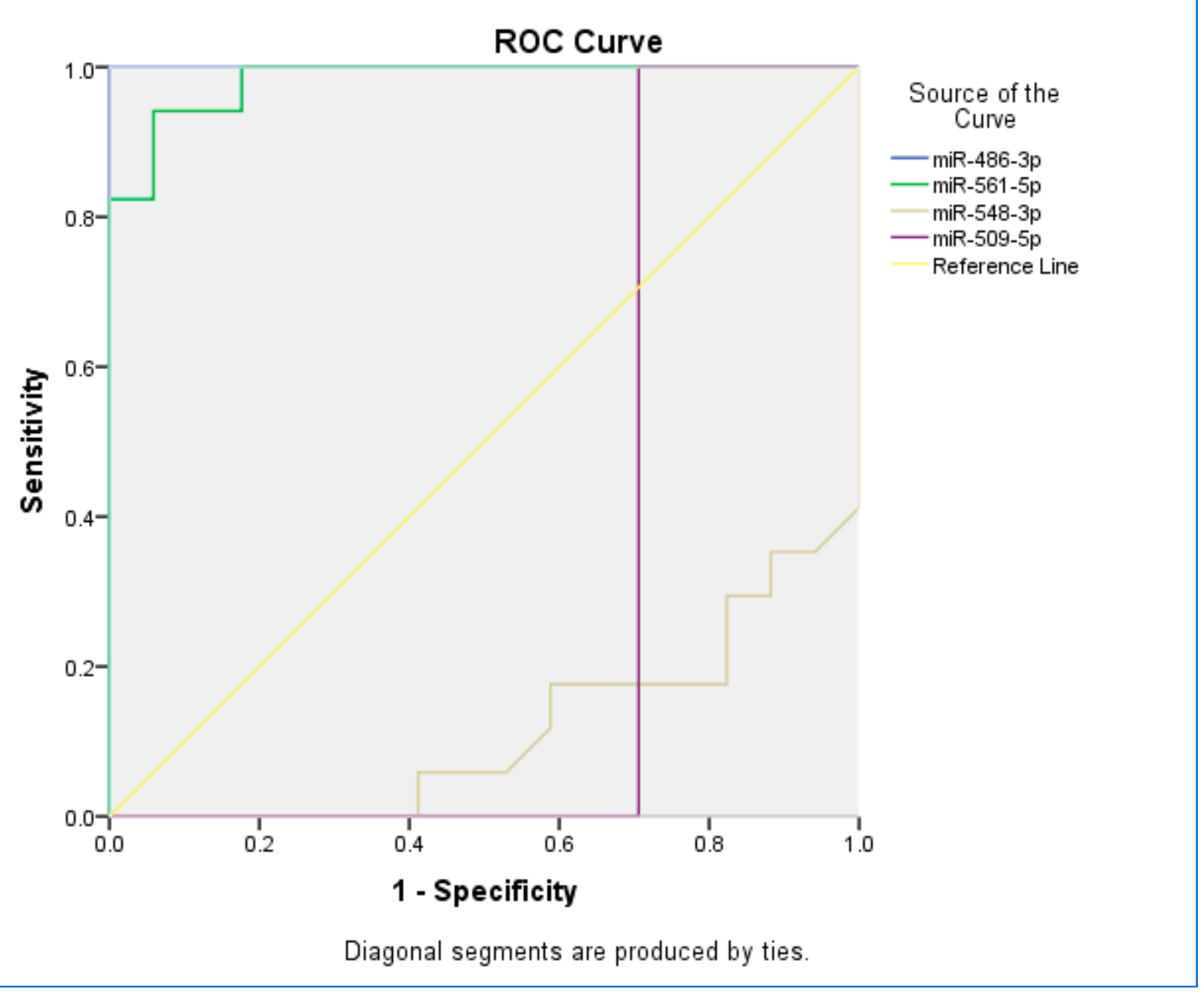

Figure 2. The receiver operating characteristic (ROC) curve for studied miRNAs.

\section{Discussion}

The key findings of the present study demonstrated that analysis of tumor tissues from Iranian patients suffering from OSCC showed that the expression of miR-486-3p and miR-561-5p were significantly lower in OSCC patients compared to controls, whereas, the expression of miR-548-3p was higher in OSCC patients compared to controls. The present 
results add to the current literature in an important way, because this preliminary data on changes in expression of miRNA are important in better understanding their target molecules and downstream pathways in OSCC. Further, the results have clinical and practical importance because such significant differences in certain miRNA are promising in the prognosis and treatment approaches of OSCC. With regards to clinical applications of miRNA in personalized medicine, specific miRNA expression profiles have been reported to predict specific clinical outcomes of dental implants; thus, such knowledge may be used as biomarkers in implant dentistry for diagnostic and prognostic purposes.

Nowadays, the studies evaluated new inhibitors [27] and antitumoral factors [28] in head and neck cancer. OSCC is the most common head and neck cancer and is one of the main causes of oral cancer-related mortality in the world due to its poor prognosis. Regardless of the accessibility of diagnostic and treatment modalities, the survival rate of OSCC is still very low. Therefore, providing personalized treatments can be beneficial for OSCC patients. Biomarkers with adequate precision and accuracy can be beneficial for physicians in predicting the prognosis of the disease. Therefore, physicians can choose the type and extent of treatment modalities, including surgery, chemotherapy, radiotherapy, and adjuvant therapy based on OSCC molecular profiles [18].

After selecting specific miRNA based on bioinformatic data, the present analysis revealed that the mean expression of miR-486-3p, miR-561-5p, and miR-548-3p was significantly different in the OSCC group compared to the control group. There was no statistically significant difference between groups in terms of the mean expression. Furthermore, the ROC analysis was used to assess the clinical implication of the miRNAs. The findings of the present study revealed that miR-486-3p can be a suitable choice for the diagnosis of OSCC, followed by miR-561-5p and miR-509-5p.

Chou et al. [23] reported that miR-486-3p undergoes downregulation in patients with OSCC. They also reported that discoidin domain receptor 1 (DDR1), a tyrosine kinase, is upregulated in tissues and OSCC cell lines and results in the progression of tumors. They concluded that restoration of miR-486-3p expression in OSCC can result in apoptosis in OSCC cells and reduce OSCC progression [23]. Studies on the differential expression of miR486-3p in the plasma of OSCC patients before and after surgery showed that the expression of miR-486-3p was associated with the risk of relapse 9-12 months after surgery. Therefore, miR-486-3p was considered as a tumor suppressor miRNA in OSCC [29]. A study [30] showed that miR-486-3p can adjust the sorafenib response in hepatocellular carcinoma (HCC), targeting both fibroblast growth factor receptor 4 (FGFR4) and epidermal growth factor (EGFR), and adjusts it to be a better treatment target than FGFR4 and EGFR inhibitors.

A study on 502 tumor tissue samples of head and neck SCC (HNSCC) and 44 nontumoral adjacent tissues revealed that miR-548f- 1 was upregulated, while miR-486-1 and miR-486-2 were downregulated in HNSCC [31]. In a study by Hiramoto et al. [32], miR-509$5 p$ was found to be associated with the worsening of survival in patients with pancreatic cancer and was considered as an independent predictive marker for mortality in pancreatic cancer. The findings of a study on patients with osteosarcoma revealed that miR-509-5p acts as a tumor suppressor miRNA by targeting TRIB2 and can be considered as an inhibitory intervention in osteosarcoma [33]. A study on the relationship between miR-509-5p and tongue SCC (TSCC) reported that the expression of this miRNA is downregulated in cell lines and tissue samples of TSCC. The authors also stated that miR-509-5p can inhibit TSCC proliferation and invasion through targeting EGFR. Therefore, the miR-509-5p/EGFR axis was considered to be capable of being a new treatment target in TSCC treatment [34].

The findings of a study on non-small cell carcinoma (NSCLC) of the lung showed that miR-561-5p is unlikely related to drug-resistant carcinoma and is considered as a potential target for antineoplastic treatment [34]. The mir-561-5p/chemokine (C-X3-C motif) ligand 1 (CX3CL1)/natural killer (NK) cell axis drives HCC metastases and shows that CX3CR1 ${ }^{+}$ NK cells act as the strong anti-tumor therapeutic factors [35]. Mir-561-5p enhances the progression of HCC and lung metastasis in vivo, without the effect of cell proliferation and invasion in vitro [36]. 
The findings of a study on breast cancer showed that high expression of miR-548-3p inhibited proliferation and facilitated apoptosis in cancer cells [37]. One research [38] identified that miR-548-3p attenuated the progression of colon cancer by targeting protein for Xenopus kinesin-like protein 2 (TPX2).

\section{Conclusions}

For the first time in this study, it was reported that the expression of miR-486-3p, miR-561-5p, miR-548-3p, and miR-509-5p was affected in Iranian patients with OSCC. The overall findings of this study indicated that the expression of miR-486-3p and miR-561-5p were significantly lower in OSCC patients compared to controls, while the expression of miR-548-3p was higher in OSCC patients compared to controls. This finding indicates the mechanism(s) by which certain microRNAs are involved in the development and progression of OSCC. Furthermore, changes in the expression of these miRNAs in cancer tissue can be considered biomarkers for the early detection of OSCC. These findings indicate the potential of miRNAs in the clinical assessment of cancers and provide new data for the development of molecule targeting treatments for oral cancers. On the other hand, this finding in terms of oral cancer markers revealed that expression of certain miRNAs which are specifically affected during tumor development are implicated in the diagnosis of early-stage OSCC. The clinical relevance of the presented study is restricted to the publication of promising preliminary results calling for more definitive large-scale investigations. It has been shown that mir-548-3p has decreased significantly in breast cancer, and its overexpression has inhibited proliferation and promoted apoptosis of breast cancer cells when inhibition was performed by regulating the expression of enoyl coenzyme A hydratase short chain 1 (ECHS1), showing the potential of mir-548-3p as a therapeutic target for breast cancer [37].

Author Contributions: Conceptualization: A.G.; methodology: A.G., A.A.; validation: H.M.; formal analysis: A.H. and M.P.; resources: A.A., M.S.; writing—original draft preparation: S.B.; writingreview and editing: M.S., A.E. and H.M.; visualization, supervision: A.G.; project administration: A.G. All authors have read and agreed to the published version of the manuscript.

Funding: This research was funded by Tehran University of Medical Sciences (grant number: 38159).

Institutional Review Board Statement: The study was approved by the Ethical Committee of the Tehran University of Medical Sciences (ethical code: IR. TUMS. DENTISTRY. REC. 1395. 1641). All tissue samples were obtained based on ethical principles. Patient identities were kept confidential and data analysis was performed on all subjects. All methods were performed in accordance with the relevant guidelines and regulations.

Informed Consent Statement: Informed consent was obtained from all individual participants included in the study. Written informed consent was obtained from patients or their guardian before starting the study.

Data Availability Statement: The datasets used and/or analyzed during the current study are available from the corresponding author on reasonable request.

Acknowledgments: This study was a part of the dissertation of Milad Parvin to perform with the support of Tehran University of Medical Sciences. We hereby thank all who helped us in conducting this study.

Conflicts of Interest: The other authors declare that they have no competing interest.

\section{Abbreviations}

OSCC: oral squamous cell carcinoma; miRNA: microRNA; q-RT-PCR: quantitative real-time PCR, UTR: untranslated region; ROC: receiver operating characteristic; AUC: area under the curve. 


\section{References}

1. Wang, Q.; Gao, P.; Wang, X.; Duan, Y. Investigation and identification of potential biomarkers in human saliva for the early diagnosis of oral squamous cell carcinoma. Clin. Chim. Acta 2014, 427, 79-85. [CrossRef] [PubMed]

2. Chang, C.-C.; Yang, Y.-J.; Li, Y.-J.; Chen, S.-T.; Lin, B.-R.; Wu, T.-S.; Lin, S.-K.; Kuo, M.Y.-P.; Tan, C.-T. MicroRNA-17/20a functions to inhibit cell migration and can be used a prognostic marker in oral squamous cell carcinoma. Oral Oncol. $2013,49,923-931$. [CrossRef] [PubMed]

3. Li, Y.; Li, B.; Xu, B.; Han, B.; Xia, H.; Chen, Q.-M.; Li, L.-J. Expression of p53, p21 CIP1/WAF1 and eIF4E in the adjacent tissues of oral squamous cell carcinoma: Establishing the molecular boundary and a cancer progression model. Int. J. Oral Sci. 2015, 7, 161-168. [CrossRef] [PubMed]

4. Malik, U.U.; Zarina, S.; Pennington, S.R. Oral squamous cell carcinoma: Key clinical questions, biomarker discovery, and the role of proteomics. Arch. Oral Biol. 2016, 63, 53-65. [CrossRef]

5. Bartel, D.P. MicroRNAs: Target recognition and regulatory functions. Cell 2009, 136, 215-233. [CrossRef]

6. Chekulaeva, M.; Filipowicz, W. Mechanisms of miRNA-mediated post-transcriptional regulation in animal cells. Curr. Opin. Cell Biol. 2009, 21, 452-460. [CrossRef]

7. Manikandan, M.; Rao, A.K.D.M.; Arunkumar, G.; Manickavasagam, M.; Rajkumar, K.S.; Rajaraman, R.; Munirajan, A.K. Oral squamous cell carcinoma: microRNA expression profiling and integrative analyses for elucidation of tumourigenesis mechanism. Mol. Cancer 2016, 15, 28. [CrossRef]

8. Miska, E.A. How microRNAs control cell division, differentiation and death. Curr. Opin. Genet. Dev. 2005, 15, 563-568. [CrossRef]

9. Avissar, M.; Christensen, B.C.; Kelsey, K.T.; Marsit, C.J. MicroRNA expression ratio is predictive of head and neck squamous cell carcinoma. Clin. Cancer Res. 2009, 15, 2850-2855. [CrossRef]

10. Fang, C.; Li, Y. Prospective applications of microRNAs in oral cancer. Oncol. Lett. 2019, 18, 3974-3984.

11. Aghbari, S.M.H.; Gaafar, S.M.; Shaker, O.G.; El Ashiry, S.; Zayed, S.O. Evaluating the accuracy of microRNA27b and microRNA137 as biomarkers of activity and potential malignant transformation in oral lichen planus patients. Arch. Dermatol. Res. 2018, 310, 209-220. [CrossRef] [PubMed]

12. Harrandah, A.M.; Fitzpatrick, S.G.; Smith, M.H.; Wang, D.; Cohen, D.M.; Chan, E.K. MicroRNA-375 as a biomarker for malignant transformation in oral lesions. Oral Surg. Oral Med. Oral Pathol. Oral Radiol. 2016, 122, 743-752.e741. [CrossRef] [PubMed]

13. Cristaldi, M.; Mauceri, R.; Di Fede, O.; Giuliana, G.; Campisi, G.; Panzarella, V. Salivary biomarkers for oral squamous cell carcinoma diagnosis and follow-up: Current status and perspectives. Front. Physiol. 2019, 10, 1476. [CrossRef] [PubMed]

14. Sukhija, H.; Krishnan, R.; Balachander, N.; Raghavendhar, K.; Ramadoss, R.; Sen, S. C-deletion in exon 4 codon 63 of p53 gene as a molecular marker for oral squamous cell carcinoma: A preliminary study. Contemp. Clin. Dent. 2015, 6, S227. [PubMed]

15. Liao, P.-H.; Chang, Y.-C.; Huang, M.-F.; Tai, K.-W.; Chou, M.-Y. Mutation of p53 gene codon 63 in saliva as a molecular marker for oral squamous cell carcinomas. Oral Oncol. 2000, 36, 272-276. [CrossRef]

16. Hema, K.; Smitha, T.; Sheethal, H.; Mirnalini, S.A. Epigenetics in oral squamous cell carcinoma. J. Oral Maxillofac. Pathol. JOMFP 2017, 21, 252. [CrossRef] [PubMed]

17. Lin, N.; Lin, Y.; Fu, X.; Wu, C.; Xu, J.; Cui, Z.; Lin, D. MicroRNAs as a Novel Class of Diagnostic Biomarkers in Detection of Oral Carcinoma: A Meta-Analysis Study. Clin. Lab. 2016, 62, 451-461. [CrossRef]

18. Troiano, G.; Mastrangelo, F.; Caponio, V.; Laino, L.; Cirillo, N.; Lo Muzio, L. Predictive prognostic value of tissue-based microRNA expression in oral squamous cell carcinoma: A systematic review and meta-analysis. J. Dent. Res. 2018, 97, 759-766. [CrossRef]

19. Zahra, A.; Rubab, I.; Malik, S.; Khan, A.; Khan, M.J.; Fatmi, M.Q. Meta-Analysis of miRNAs and their involvement as biomarkers in oral cancers. BioMed Res. Int. 2018, 2018, 8439820. [CrossRef]

20. Zeljic, K.; Jovanovic, I.; Jovanovic, J.; Magic, Z.; Stankovic, A.; Supic, G. MicroRNA meta-signature of oral cancer: Evidence from a meta-analysis. Upsala J. Med. Sci. 2018, 123, 43-49. [CrossRef]

21. Hedbäck, N.; Jensen, D.H.; Specht, L.; Fiehn, A.-M.K.; Therkildsen, M.H.; Friis-Hansen, L.; Dabelsteen, E.; von Buchwald, C. MiR-21 expression in the tumor stroma of oral squamous cell carcinoma: An independent biomarker of disease free survival. PLoS ONE 2014, 9, e95193. [CrossRef] [PubMed]

22. Søkilde, R.; Persson, H.; Ehinger, A.; Pirona, A.C.; Fernö, M.; Hegardt, C.; Larsson, C.; Loman, N.; Malmberg, M.; Rydén, L. Refinement of breast cancer molecular classification by miRNA expression profiles. BMC Genom. 2019, 20, 503. [CrossRef] [PubMed]

23. Chou, S.-T.; Peng, H.-Y.; Mo, K.-C.; Hsu, Y.-M.; Wu, G.-H.; Hsiao, J.-R.; Lin, S.-F.; Wang, H.-D.; Shiah, S.-G. MicroRNA-486-3p functions as a tumor suppressor in oral cancer by targeting DDR1. J. Exp. Clin. Cancer Res. 2019, 38, 281. [CrossRef] [PubMed]

24. Wang, Z.; Wu, X.; Hou, X.; Zhao, W.; Yang, C.; Wan, W.; Chen, L. miR-548b-3p functions as a tumor suppressor in lung cancer. Lasers Med. Sci. 2020, 35, 833-839. [CrossRef] [PubMed]

25. Liao, Z.; Zheng, Q.; Wei, T.; Zhang, Y.; Ma, J.; Zhao, Z.; Sun, H.; Nan, K. MicroRNA-561 affects proliferation and cell cycle transition through PTEN/AKT signaling pathway by targeting P-REX2a in NSCLC. Oncol. Res. 2020, 28, 147. [CrossRef] [PubMed]

26. Ma, N.; Zhang, W.; Qiao, C.; Luo, H.; Zhang, X.; Liu, D.; Zang, S.; Zhang, L.; Bai, J. The tumor suppressive role of MiRNA-509-5p by targeting FOXM1 in non-small cell lung cancer. Cell. Physiol. Biochem. 2016, 38, 1435-1446. [CrossRef] 
27. Zhang, L.; Gülses, A.; Purcz, N.; Weimer, J.; Wiltfang, J.; Açil, Y. A comparative assessment of the effects of integrin inhibitor cilengitide on primary culture of head and neck squamous cell carcinoma (HNSCC) and HNSCC cell lines. Clin. Transl. Oncol. 2019, 21, 1052-1060. [CrossRef]

28. Açil, Y.; Torz, K.; Gülses, A.; Wieker, H.; Gerle, M.; Purcz, N.; Will, O.M.; Meyer, J.E.; Wiltfang, J. An experimental study on antitumoral effects of KI-21-3, a synthetic fragment of antimicrobial peptide LL-37, on oral squamous cell carcinoma. $J$. Cranio-Maxillofac. Surg. 2018, 46, 1586-1592. [CrossRef]

29. Yan, Y.; Wang, X.; Venø, M.T.; Bakholdt, V.; Sørensen, J.A.; Krogdahl, A.; Sun, Z.; Gao, S.; Kjems, J. Circulating miRNAs as biomarkers for oral squamous cell carcinoma recurrence in operated patients. Oncotarget 2017, 8, 8206. [CrossRef]

30. Ji, L.; Lin, Z.; Wan, Z.; Xia, S.; Jiang, S.; Cen, D.; Cai, L.; Xu, J.; Cai, X. miR-486-3p mediates hepatocellular carcinoma sorafenib resistance by targeting FGFR4 and EGFR. Cell Death Dis. 2020, 11, 250. [CrossRef]

31. Fang, X.-N.; Yin, M.; Li, H.; Liang, C.; Xu, C.; Yang, G.-W.; Zhang, H.-X. Comprehensive analysis of competitive endogenous RNAs network associated with head and neck squamous cell carcinoma. Sci. Rep. 2018, 8, 10544. [CrossRef] [PubMed]

32. Hiramoto, H.; Muramatsu, T.; Ichikawa, D.; Tanimoto, K.; Yasukawa, S.; Otsuji, E.; Inazawa, J. miR-509-5p and miR-1243 increase the sensitivity to gemcitabine by inhibiting epithelial-mesenchymal transition in pancreatic cancer. Sci. Rep. 2017, 7, 4002. [CrossRef] [PubMed]

33. Guo, J.; Wu, Q.; Peng, X.; Yu, B. miR-509-5p inhibits the proliferation and invasion of osteosarcoma by targeting TRIB2. BioMed Res. Int. 2019, 2019, 252303. [CrossRef] [PubMed]

34. Hou, C.; Dong, Y.; Zhang, F.; Du, B. MicroRNA-509 acts as a tumor suppressor in tongue squamous cell carcinoma by targeting epidermal growth factor receptor. Mol. Med. Rep. 2017, 16, 7245-7252. [CrossRef]

35. Chen, E.-B.; Zhou, Z.-J.; Xiao, K.; Zhu, G.-Q.; Yang, Y.; Wang, B.; Zhou, S.-L.; Chen, Q.; Yin, D.; Wang, Z. The miR-561-5p/CX3CL1 signaling axis regulates pulmonary metastasis in hepatocellular carcinoma involving CX3CR1+ natural killer cells infiltration. Theranostics 2019, 9, 4779. [CrossRef]

36. Ghafouri-Fard, S.; Tamizkar, K.H.; Hussen, B.M.; Taheri, M. MicroRNA signature in liver cancer. Pathol. Res. Pract. 2021, 219, 153369. [CrossRef]

37. Shi, Y.; Qiu, M.; Wu, Y.; Hai, L. MiR-548-3p functions as an anti-oncogenic regulator in breast cancer. Biomed. Pharmacother. 2015, 75, 111-116. [CrossRef]

38. Wang, M.; Yang, M.; Deng, B. miR-548a-3p Weakens the Tumorigenesis of Colon Cancer Through Targeting TPX2. Cancer Biother. Radiopharm. 2020, 427, 79-85. [CrossRef] 